\title{
Efeitos ecotoxicológicos de metais aos organismos aquáticos
}

Ecotoxicological effects of metals to aquatic organisms

Efectos ecotoxicológicos de metales a los organismos acuáticos

Márjori Brenda Leite Marques Mestranda em Engenharia Civil, UNESP - Ilha Solteira/SP, Brasil. marjori_brenda@hotmail.com

Juliana Heloisa Pinê Américo-Pinheiro Professora Doutora, Universidade Brasil (UNIVBRASIL), Brasil. americo.ju@gmail.com 


\section{RESUMO}

Em ecossistemas aquáticos, a presença de metais pesados são características oriundas de processos naturais, tais como, processos geológicos e físicos, mas também ou antrópicos como a aplicação de agrotóxicos, efluentes industriais, domésticos e mineração. Nos corpos hídricos os metais tendem a se acumular no sedimento sendo liberado em colunas d'agua e incorporados ao longo da cadeia alimentar, podendo afetar afetando a biota, sendo incorporados ao longo da cadeia alimentar e consequentemente podendo causar danos irreversíveis nos aos ecossistemas. Esse trabalho objetivou analisar a ecotoxicidade de metais pesados em organismos de diferentes níveis tróficos por meio de uma revisão bibliográfica sobre trabalhos que visaram avaliaram o efeito agudo e crônico de metais em organismos, focando nas consequências observadas correlacionando o tipo de metal e aos diferentes bioensaios.

PALAVRAS-CHAVE: Mercúrio. Cobre. Danio rerio.

\section{ABSTRACT}

In aquatic ecosystems, the presence of heavy metals are characteristics derived from natural processes, such as geological and physical processes, but also or anthropic as the application of agrochemicals, industrial, domestic effluents and mining. In water bodies metals tend to accumulate in the sediment being released into water columns and incorporated along the food chain, which can affect affecting the biota, being incorporated along the food chain and consequently causing irreversible damages to the ecosystems. This work aimed to analyze the ecotoxicity of heavy metals in organisms of different trophic levels through a bibliographical review on works that aimed to evaluate the acute and chronic effect of metals in organisms, focusing on the observed consequences correlating the type of metal and the different bioassays.

KEYWORDS: Mercury. Copper. Danio rerio.

\section{RESUMEN}

En los ecosistemas acuáticos, la presencia de metales pesados son características oriundas de procesos naturales, tales como procesos geológicos y físicos, pero también o antrópicos como la aplicación de agrotóxicos, efluentes industriales, domésticos y minería. En los cuerpos hídricos los metales tienden a acumularse en el sedimento siendo liberado en columnas de agua e incorporados a lo largo de la cadena alimentaria, pudiendo afectar afectando la biota, siendo incorporados a lo largo de la cadena alimentaria y consecuentemente pudiendo causar daños irreversibles en los ecosistemas. Este trabajo objetivó analizar la ecotoxicidad de metales pesados en organismos de diferentes niveles tróficos a través de una revisión bibliográfica sobre trabajos que visaron evaluaron el efecto agudo y crónico de metales en organismos, enfocando en las consecuencias observadas correlacionando el tipo de metal y los diferentes bioensayos.

PALABRAS CLAVE: Mercúrio. Cobre. Danio rerio. 


\section{INTRODUÇÃO}

Os metais pesados como zinco, ferro, alumínio entre outros, são essenciais para determinados ecossistemas, sendo benéficos para o desenvolvimento de algumas plantas. No entanto, outros metais pesados como arsênio, cádmio, chumbo, mercúrio e cromo são tóxicos, mas mesmo assim estão presentes em diversos tipos de fertilizantes. Há limites toleráveis de teores de concentrações que podem ser admitidas nesse tipo de produto. Entre os principais riscos estão a degradação da qualidade do solo e a poluição das fontes de água e da atmosfera, que são causadas pela presença de substâncias como metais pesados em fertilizantes. Eles também podem proporcionar sérios riscos aos seres vivos (ECYCLE, 2018).

Os limites variam de acordo com a legislação de cada país, o que demonstra orientações não uniformes no estabelecimento dessas normas e a necessidade de estudos mais aprofundados a respeito. No Brasil, os teores são determinados pelo Ministério da Agricultura, Pecuária e Abastecimento (MAPA, 2018), na Regulamentação de Insumos Agrícolas.

Entre outras fontes de contaminação por metais pesados, estão as baterias e as pilhas. $\mathrm{O}$ crescente consumo de pilhas e baterias é um dos problemas a ser enfrentado, uma vez que esses produtos contêm em sua composição diversas substancias químicas.

Esses produtos, ao serem descartados juntamente com o lixo comum, podem provocar danos ao meio ambiente e representam riscos à saúde pública, pela possibilidade dos metais pesados atingirem o organismo por meio da cadeia alimentar. A compostagem de resíduos sólidos urbanos é um exemplo, pois a utilização do composto orgânico em culturas agrícolas propicia a absorção de metais pesados, mediante a ingestão por animais e humanos. Os metais pesados, por serem bioacumulativos, acabam depositando-se em determinados pontos do organismo, vindo a afetar suas funções orgânicas. Além disso, as substâncias tóxicas que compõem as pilhas e baterias, quando dispostas inadequadamente, podem atingir e contaminar os aquíferos freáticos e chegar ao organismo humano através da ingestão (água ou alimentos contaminados), da inalação ou contato dérmico (REIDLER, 2000).

A toxicidade de um metal, assim como sua disponibilidade (capacidade de interação de um contaminante com um sistema biológico) estão relacionadas com vários fatores, como: a forma química em que o metal se encontra no ambiente; as vias de introdução do metal nos organismos vivos; a sua capacidade de biotransformação em sub-produtos mais ou menos tóxicos, etc. Desta forma, da sua emissão para o ambiente até o aparecimento dos sintomas da intoxicação, vários serão os interferentes que influirão nos efeitos negativos causados pelos metais. (MINISTÉRIO DA SAÚDE, 2008).

Esse trabalho objetivou avaliar a ecotoxicidade de metais pesados em organismos aquáticos por meio de um levantamento bibliográfico acerca de trabalhos que analisaram o efeito agudo e crônico de metais para organismos de diferentes níveis tróficos.

\section{A DINÂMICA DOS METAIS PESADOS NO AMBIENTE}

Os metais entre outras substâncias químicas podem chegar em corpos hídricos pelos processos químicos e físicos naturais, tais como intemperismo, sedimentação e lixiviação, e pelos processos antrópicos como lixões e efluentes domésticos e industriais. Nos processos 
naturais, a lixiviação ocorre por meio de processos como chuva e vento, onde os metais já presentes naturalmente em solos e plantas decorrem para os corpos hídricos. A lixiviação refere-se à ação de qualquer processo de extração ou solubilização seletiva de constituintes químicos de uma rocha, mineral, depósito sedimentar, solo, etc, pela ação de um fluido percolante (SIGEP, 2018).

A poluição do solo e de sistemas aquáticos por metais pesados é um fator que afeta a qualidade do meio ambiente e constitui risco eminente de intoxicação ao ser humano. Nos últimos anos, foram realizadas inúmeras pesquisas com a finalidade de avaliar os possíveis impactos ambientais relacionados ao aumento da concentração de metais pesados no meio ambiente. Esses metais são originários de processos litogênicos e/ou atividades antrópicas, como a utilização de fertilizantes em zonas agrícolas e a atividade mineradora (MUNIZ; OLIVEIRA-FILHO, 2006).

\subsection{Fertilizantes}

Os fertilizantes podem ser considerados contaminantes, por causarem desvios na composição normal do meio ambiente, quando fornecem quantidades variáveis de elementos traços, muitos deles reconhecidos como metais pesados e outros como micronutrientes. $\mathrm{O}$ uso de fertilizantes no solo deve obedecer sistematicamente às recomendações agronômicas, mediante análises prévias da fertilidade do solo. Por se tratar de corpos estranhos ao solo, as reações e alterações processam-se física, química e biologicamente podendo causar efeitos negativos no agroecossistema (EMBRAPA, 2018).

Segundo Wauchope et al. (2004), fertilizantes, agrotóxicos entre outros produtos de uso agrícola são altamente solúveis em água, sendo facilmente transportados a jusante de campos agrícolas para áreas superficiais de corpos hídricos durante a chuva e até mesmo na prática da irrigação. No entanto, os pesticidas adsorvidos no solo, também podem ser movidos através de movimentos suspensos de partículas e sedimentos durante eventos de chuvas intensas.

De acordo com Vryzas (2018), fertilizantes e pesticidas podem atingir as águas superficiais de corpos hídricos e as águas subterrâneas por dois tipos de poluição: difusa e pontual. A contaminação difusa por compostos químicos de fertilizantes e pesticidas é responsável pela deteç̧ão generalizada de baixas concentrações desses compostos químicos, enquanto fontes pontuais resultam na deteç̧ão de alta concentração de destes compostos. Existem inúmeras maneiras de fertilizantes e pesticidas atingirem e contaminarem os corpos d'água superficiais. A aplicação por pulverização ou o plantio de sementes revestidas com pesticidas e fertilizantes e a dispersão do vento levam à contaminação direta das águas superficiais. A dissipação dos compostos presentes nestes produtos no meio aquoso, variam em termos de temperatura, pH, luz solar, presença de matéria orgânica dissolvida, material em suspensão, algas, zooplâncton, peixes e microrganismos.

\subsection{Efluentes industriais}

A atividade industrial tem contribuído para um aumento significativo nas concentrações de íons metálicos em águas, representando uma importante fonte de contaminação dos corpos 
aquáticos, principalmente quando consideramos que tais íons podem ser disseminados via cadeia alimentar. Os efluentes líquidos industriais apresentam composição química bastante complexa, contendo compostos orgânicos e inorgânicos. O método mais utilizado no tratamento de efluentes líquidos contendo matéria orgânica é o biológico. No entanto, a presença de compostos inorgânicos pode inibir este processo. Neste caso, é necessário realizar uma etapa de tratamento químico antes da realização do tratamento biológico, visando a remoção desta carga inorgânica. O tratamento clássico de efluentes contendo metais pesados envolve processos físico-químicos de precipitação, troca iônica, adsorção e extração por solventes (JIMENEZ, 2004).

Dentre as principais fontes poluentes dos mananciais aquáticos, destaca-se a indústria de galvanoplastia, que manipula metais extremamente nocivos à saúde pública, tais como níquel, cádmio, cromo, cobre e zinco, durante seus processos de eletroplatinação (Quadro 1). Estas empresas costumam trabalhar com elevados teores de metais e terminam por descartar seus resíduos diretamente no fluxo das águas, perturbando o equilíbrio ambiental aquático e contaminando o solo da região. Uma vez ingerido, os metais passam a se acumular nos tecidos dos órgãos, provocando efeitos extremamente indesejáveis à saúde pública (HILÁRIO et al., 2007).

Quadro 1: Lista de metais pesados mais nocivos aos seres vivos e suas consequências no corpo humano

\begin{tabular}{|c|c|c|}
\hline Metais & Origem & Efeitos no ser humano \\
\hline Alumínio & $\begin{array}{c}\text { Produção de artefatos de alumínio; serralheria, soldagem de } \\
\text { medicamentos (antiácidos) e tratamento convencional de } \\
\text { água. }\end{array}$ & $\begin{array}{l}\text { Anemia por deficiência de ferro, } \\
\text { intoxicação crônica. }\end{array}$ \\
\hline Arsênico & Metalúrgica, manufatura de vidros e fundição. & Câncer (seios paranasais) \\
\hline Cádmio & Soldas, tabaco, baterias e pilhas. & $\begin{array}{l}\text { Câncer de pulmões e próstata; } \\
\text { lesões nos rins. }\end{array}$ \\
\hline Chumbo & $\begin{array}{c}\text { Fabricação e reciclagem de baterias de autos, indústrias de } \\
\text { tintas, pintura em cerâmica, soldagem. }\end{array}$ & $\begin{array}{l}\text { Saturrismo (cólicas abnominais, } \\
\text { tremores, fraqueza muscular, } \\
\text { lesão renal e cerebral. }\end{array}$ \\
\hline Cobalto & Preparo de ferramentas de cortes e furadoras. & Fibrose pulmonar \\
\hline Cromo & $\begin{array}{l}\text { Indústria de corantes, esmaltes, tintas, ligas com aço e } \\
\text { níquel, cromagem de metais. }\end{array}$ & Asma e câncer \\
\hline $\begin{array}{l}\text { Fósforo } \\
\text { amarelo }\end{array}$ & Veneno para baratas, inseticidas e fogos de artifícios. & $\begin{array}{l}\text { Náuseas. Gastrite, fezes e } \\
\text { vômitos fosforescentes, dor } \\
\text { muscular. }\end{array}$ \\
\hline Mercúrio & $\begin{array}{c}\text { Moldes industriais, industrias de cloro soda, garimpo de } \\
\text { ouro, lâmpadas fluorescentes. }\end{array}$ & $\begin{array}{l}\text { Intoxicação do sistema nervoso } \\
\text { central }\end{array}$ \\
\hline Níquel & $\begin{array}{l}\text { Baterias, aramados, fundição, niquelagem de metais, } \\
\text { refinarias. }\end{array}$ & $\begin{array}{l}\text { Câncer de pulmões e seios } \\
\text { paranasais }\end{array}$ \\
\hline $\begin{array}{c}\text { Fumos } \\
\text { Metálicos }\end{array}$ & $\begin{array}{l}\text { Vapores de soldagem industrial, ou da galvarização de } \\
\text { metais }\end{array}$ & $\begin{array}{l}\text { Febre, tosse, cansaço e dores } \\
\text { musculares. }\end{array}$ \\
\hline
\end{tabular}

Fonte: SINDIPETRO, 2018. 


\subsection{Mineração}

A mineração é uma das atividades econômicas que mais provoca contaminação pelo mercúrio, causando risco não só aos garimpeiros, mas às populações que vivem próximo a garimpos, ou que se alimentam de pescados ou ingerem água contaminada. No processo de busca por ouro, ao separar o metal de outros minerais da terra, o mercúrio é queimado junto a todos os materiais encontrados, o que gera fumaça tóxica e contaminação da natureza, garimpeiros e comunidades. O metal acaba ficando disponível no meio ambiente e até mesmo o solo e a água tornam-se focos para contaminação em larga escala. (MINISTÉRIO DA SAÚDE, 2008).

Um dos grandes problemas da mineração na atualidade está relacionado com os rejeitos decorrentes dessa atividade, como a extração de ouro, caulim e carvão mineral, pois contribuem para o aumento de metais pesados no solo e em sistemas aquáticos. Esses metais muitas vezes estão associados a problemas de contaminação do ambiente e do próprio ser humano. Para determinar a ocorrência destes metais no meio ambiente, é necessário compreender os processos que controlam a sua mobilidade e que os tornam biodisponíveis. Uma vez que o animal ou o ser humano pode entrar em contato com esses contaminantes, torna-se necessário conhecer, entre outras coisas, a toxicidade desses compostos, para evitar desastres históricos como os que se tem notícia (MUNIZ; OLIVEIRA-FILHO, 2006).

De acordo com Penna (2009), a mineração consome grandes de água em diferentes fatores da mineração:

- Na pesquisa mineral (sondas rotativas e amostragens);

- Na lavra (desmonte hidráulico, bombeamento de água de minas subterrâneas etc);

- No beneficiamento (britagem, moagem, flotação, lixiviação etc);

- No transporte por mineroduto e na infraestrutura (pessoal, laboratórios etc).

Penna (2009), ainda afirma que existem casos em que o rebaixamento do lençol freático para o desenvolvimento da lavra é necessário, acarretando em uma série de impactos aos corpos hídricos, onde uma série de impactos podem ocorrer, tais como: aumento da turbidez e consequente variação na qualidade da água e na penetração da luz solar no interior do corpo hídrico; alteração do pH da água, tornando-a geralmente mais ácida; derrame de óleos, graxas e metais pesados (altamente tóxicos, com sérios danos aos seres vivos do meio receptor); redução do oxigênio dissolvido dos ecossistemas aquáticos; assoreamento de rios; poluição do ar, principalmente por material particulado; perdas de grandes áreas de ecossistemas nativos ou de uso humano.

Além disso, a produção de lâmpadas fluorescentes, equipamentos para medir a pressão arterial, termômetros e o processo produtivo de cloro e soda (técnica baseada em mercúrio), também são fontes de mercúrio. Além da área de saúde bucal com o uso do amálgama (bastante usado em restaurações de dentes). Conforme a representante do Ministério do Meio Ambiente, o uso e a substituição do metal nessas atividades estão sendo fruto das discussões do acordo internacional, que busca, dentre outras coisas, encontrar saídas para o setor industrial modificar os processos produtivos que utilizam o metal (MINISTÉRIO DO MEIO AMBIENTE, 2018). 


\section{BIOACUMULAÇÃO DE METAIS PESADOS EM ORGANISMOS VIVOS}

Os contaminantes orgânicos dissolvem-se e se acumulam nas fases orgânicas de animais e plantas. $O$ enriquecimento líquido de contaminantes em relação ao ambiente é descrito pelo processo de bioacumulação. A bioacumulação é o resultado líquido de todos os processos de absorção e adsorção, como absorção respiratória e dietética, difusão passiva, metabolismo, transferência para a prole e crescimento. Mesmo se absorvido por um organismo, não resulta automaticamente na bioacumulação do contaminante. Um organismo pode modificar a mistura absorvida de contaminante; alguns produtos químicos são retidos, enquanto outros que são mais solúveis em água ou degradáveis, são eliminados do corpo, resultando em nenhum acúmulo de líquido. Na teia alimentar, os animais mostram uma bioacumulação muito diferente de vários produtos químicos, tanto em níveis como na composição relativa (BORGA, 2013). Dentre os principais metais pesados que causam efeitos em seres vivos destacam-se o mercúrio, cádmio, chumbo e o alumínio (Quadro 2).

Quadro 2: Metais pesados e seus efeitos ecotoxicológicos

\begin{tabular}{|c|c|c|c|}
\hline Metais & Seres vivos & Efeitos ecotoxicológicos & Autores \\
\hline Alumínio & -Charophyceae (alga) & $\begin{array}{c}\text { - Cloroses, necroses, descolamento do córtex e } \\
\text { amolecimento do tálus. }\end{array}$ & $\begin{array}{l}\text { - Rybak et al., } \\
\text { (2017). }\end{array}$ \\
\hline Chumbo & $\begin{array}{l}\text {-Phanerochaete } \\
\text { chrysosporium (alga) } \\
\text {-Athyrium wardii (planta) } \\
\text {-Lolium perenne (planta) }\end{array}$ & $\begin{array}{l}\text {-Alta capacidade de acumulação e alta } \\
\text { tolerância. } \\
\text { - Inibição do crescimento. } \\
\text {-Baixas concentrações: auxilia na remediação, } \\
\text { altas concentrações: inibição de crescimento }\end{array}$ & $\begin{array}{l}\text { - Huang et al., } \\
\text { (2018). } \\
\text { - Zhan et al., } \\
\text { (2018). } \\
\text {-Huang, (2018. }\end{array}$ \\
\hline Cádmio & $\begin{array}{l}\text {-Athyrium wardii (planta) } \\
\text {-Danio rerio (peixe) }\end{array}$ & $\begin{array}{c}\text { - Inibição do crescimento } \\
\text {-Diminuição da fertilidade e degeneração das } \\
\text { células da retina }\end{array}$ & $\begin{array}{l}\text {-Zhan et al., } \\
\text { (2018). } \\
\text {-Acosta et al., } \\
\text { (2016). } \\
\text {-Avallone et al., } \\
\text { (2015). }\end{array}$ \\
\hline Cromo & - Salmo gairdneri (peixe) & -Inibição da atividade enzimática & $\begin{array}{l}\text {-Bogé et al., } \\
\text { (1987). }\end{array}$ \\
\hline Níquel & $\begin{array}{l}\text { - Acropora aspera, } \\
\text { Acropora digitifera, } \\
\text { Platygyra daedalea } \\
\text { (corais). }\end{array}$ & - Inibição da fertilização. & $\begin{array}{c}\text { - Gissi et al., } \\
\text { (2017). }\end{array}$ \\
\hline Cobre & $\begin{array}{l}\text { - Acropora aspera, } \\
\text { Acropora digitifera, } \\
\text { Platygyra daedalea } \\
\text { (corais). }\end{array}$ & - Inibição da fertilização. & $\begin{array}{c}\text { - Gissi et al., } \\
\text { (2017). }\end{array}$ \\
\hline Mercúrio & $\begin{array}{l}\text { - P. corethrurus } \\
\quad \text { (anelídeo) } \\
\text {-Enguias europeias } \\
\text { - Corbicula fluminea } \\
\text { (molusco bivalve) }\end{array}$ & $\begin{array}{l}\text {-Movimento e habilidade, inibição de } \\
\text { crescimento, reprodução e desenvolvimento } \\
\text { - Bioacumulação e baixa eficiência de } \\
\text { reprodução. } \\
\text { - Inibição de atividade enzimática, hipóxia e } \\
\text { diminuição da energia. }\end{array}$ & $\begin{array}{l}\text {-Buch et al., } \\
\text { (2017). } \\
\text {-Nowosad et al., } \\
\text { (2018). } \\
\text { - Oliveira et al., } \\
\text { (2018). }\end{array}$ \\
\hline
\end{tabular}


A acumulação de mercúrio nos solos é um problema ambiental de larga escala esperado para as próximas décadas nos ecossistemas terres-experimentais. O mercúrio lentamente acumulado nos solos pode exercer um importante processo de seleção natural em relação às espécies ou grupos taxonômicos que são mais tolerantes a este metal traço. Também pode resultar na perda de espécies inabitáveis e na perda de funcionalidade do solo e no fornecimento de serviços ecossistêmicos afetados por essas espécies (BUCH et al., 2017).

O alumínio é um dos metais mais abundantes na crosta terrestre e, paradoxalmente, não tem função biológica conhecida. O alumínio é bioquimicamente reativo, é simplesmente que não é necessário para nenhum processo essencial na biota existente. Não há evidência nem de bioquímica de alumínio específica para o elemento nem conservada evolutivamente. Isto significa que não existem ligações específicas para o seu transporte, não existem transportadores ou canais para facilitar seletivamente a sua passagem pelas membranas, não existem proteínas de armazenamento intracelular para ajudar a sua homeostase celular e não existem vias que evoluíram para permitir o metabolismo e excreção de alumínio. É claro que o alumínio é encontrado em todos os compartimentos de todas as células de todos os organismos, do vírus ao homem (EXLEY; MOLD, 2015).

O cádmio é um elemento natural encontrado na crosta terrestre; geralmente está associada a outros metais, mas devido aos impactos causados pela atividade humana, sua concentração aumentou no meio aquático. Este metal pode danificar a reprodução de animais aquáticos, diminuindo a taxa de fertilização de organismos como peixes (ACOSTA, 2016).

O chumbo é um metal tóxico, pesado, macio, maleável e pobre condutor de eletricidade. É um metal conhecido e usado desde a antiguidade. Suspeita-se que o chumbo está sendo usado pelos humanos por, pelo menos, 7000 anos, porque era (e continua sendo) muito difundido na natureza e de fácil extração. Também é fácil de ser trabalhado por ser altamente maleável, ductil e de baixo ponto de fusão. É usado na construção civil, baterias de ácido, em munição, proteção contra raios-X. Forma ligas metálicas para a produção de soldas, fusíveis, revestimentos de cabos elétricos, materiais antifricção, metais de tipografia, etc. 0 chumbo tem o número atômico mais elevado entre todos os elementos estáveis (ICZ, 2018).

Devido à sua aplicação na gasolina com objetivo de melhorar o desempenho dos motores, dando-lhes maiores potência e economia de combustível, o chumbo passou a ser fonte de contaminação do meio ambiente, pois quando lançado na atmosfera na forma particulada, essas partículas são transportadas por longas distâncias e se acumulam por deposição seca ou úmida em outros locais (ECYCLE, 2018).

A Agência Internacional de Pesquisa sobre o Câncer (IARC) classificou os compostos de chumbo inorgânicos como provavelmente cancerígenos para os seres humanos. Além disso, estudos indicam o chumbo como um disruptor endócrino, podendo alterar a forma natural de regulação hormonal do organismo.

\section{CONSIDERAÇÕES FINAIS}

A poluição das águas superficiais e subterrâneas com metais pesados oriundos principalmente de atividades antrópicas, é uma grave preocupação global, no âmbito ecológico e também tanto ambientalmente quanto no que diz respeito à da saúde humana. Os dados reunidos 
neste trabalho sumarizam os principais metais de alta toxicidade, no âmbito da contaminação de ecossistemas aquáticos, enfatizando os riscos apresentados pela As altas concentrações desses elementos apresentam sérios riscos aos ecossistemas aquáticos e também para outras formas de vida devido à bioacumulação e aos efeitos ecotoxicológicos em organismos de diferentes níveis tróficos.

\section{AGRADECIMENTOS}

À Coordenação de Aperfeiçoamento de Pessoal de Nível Superior (Capes) pela concessão da bolsa de mestrado da primeira autora.

\section{REFERÊNCIAS BIBLIOGRÁFICAS}

ACOSTA, B.,I., JUNIOR,V.,S., A., SILVA, F., E., CARDOSO, F., T., CALDAS, S., J., JARDIM, D., J., CORCINI, D., C. Effects of exposure to cadmium in sperm cells of zebrafish, Danio rerio. Toxicology Reports, v.3, p. 696-700, 2016.

AVALLONE, B., CRISPINO, R., CERCIELLO, R., SIMONIELLO, P., PANZUTO, R., MOTTA, M., C. Cadmium effects on the retina of adult Danio rerio. Comptes Rendus Biologies, v.338, p. 40-47,2015.

BOGÉ, G., BUSSIERE, D., PÉRES, G. Effets Du Chrome Hexavalent Sur Les Fonctions De La Bordure En Brosse De L'intestin De La Truite Arc En Ciel (Salmo Gairdneri R.), Water Research, v. 22, p. 441-447, 1987.

BORGA, K., Ecotoxicology: Bioaccumulation, Reference Module in Earth Systems and Environmental Sciences, p. 346-348, 2013.

BUCH, C., A., BROWN, G., G., CORREIA, F., E., M., LOURENÇATO, F., L., FILHO, S., V., E. Ecotoxicology of mercury in tropical forest soils: Impact on earthworms. Science of the Total Environment, v.589, p.222-231, 2017.

ECYCLE (SUA PEGADA MAIS LEVE). Disponível em: <https://www.ecycle.com.br/> Acesso em: 21/05/2018.

EMPRESA BRASILEIRA DE PESQUISA AGROPECUÁRIA - EMBRAPA, 2018. Disponível em :< http://www.agencia.cnptia.embrapa.br/gestor/agricultura_e_meio_ambiente/arvore/CONTAG01_38_2102007928 14.html > Acesso em: 15/05/2018.

EXLEY, C., MOLD, J., M. The binding, transport and fate of aluminium in biological cells. Journal of Trace Elements in Medicine and Biology, v.30, p. 90-95, 2015.

GISSI, F., STAUBERC, J., REICHELT-BRUShetTD, A., HARRISOND, L., P., JOLLEYA, F., D. Inhibition in fertilisation of coral gametes following exposure to nickel and copper, Ecotoxicology and Environmental Safety, v.145, p.3241,2017 .

GLOSSÁRIO GEOLÓGICO ILUSTRADO - SIGEP - CPRM, 2018. Disponível em: < http://sigep.cprm.gov.br/glossario/verbete/lixiviacao.htm> .Acesso em 17/05/2018.

HILÁRIO, S., L., MORAIS, E. F., LIMA, B., S., M., PEREIRA, C. P. "Remoção de alguns metais pesados de efluentes industriais e descartes de laboratórios químicos" Associação Norte Nordeste de Química - ANNQ, 2007. Disponível em < annq.org/congresso2007/trabalhos_apresentados/T3.pdf> Acesso em: 11/05/2018. 
HUANG, C., WANG, R., ZENG, G., HUANG, D., LAI, C., ZHANG, J., XIAO, Z., WAN, J., XU, P., GONG, X., XUE, W., REN, X. Transcriptome analysis reveals novel insights into the response to $\mathrm{Pb}$ exposure in Phanerochaete chrysosporium, Chemosphere, v. 194, p.657-665, 2018.

HUANG, D., QIN, X., PENG, Z., LIU, Y., GONGA, X., ZENG, G., HUANG, C., CHENG, M., XUE, W., WANG, X., HU, Z. Nanoscale zero-valent iron assisted phytoremediation of $\mathrm{Pb}$ in sediment: Impacts on metal accumulation and antioxidative system of Lolium perenne. Ecotoxicology and Environmental Safety, v.153, p.229-237, 2018.

INSTITUTO DE METAIS NÃO FERROSOS, (ICZ, 2018). Disponível em: <http://www.icz.org.br/chumbo-sociedade.php> Acesso em: 21/05/2018.

INTERNATIONAL AGENCY FOR RESEARCH ON CANCER, (IARC,2018). Disponível em: <https://www.iarc.fr/> Acesso em: $15 / 05 / 2018$

JIMENEZ, S., R., DAL BOSCO, M., S., CARVALHO, W., A., Remoção de metais pesados de efluentes aquosos pela zeólita natural escolecita - Influência da temperatura e do ph na adsorção em sistemas monoelementares, Quimica Nova na Escola, v. 27, p.734-738, 2004.

MINISTÉRIO DA AGRICULTURA PECUÁRIA E ABASTECIMENTO (MAPA, 2018). Disponível em:<http://www.agricultura.gov.br/assuntos/insumos-agropecuarios/insumos-agricolas/fertilizantes> Acesso em $17 / 05 / 2018$.

MINISTÉRIO DA SAÚDE, 2008. Parecer Técnico № 070 CGVAM/SVS/MS/2008. Disponível em : < http://www.mma.gov.br/port/conama/processos/0330EB12/ParecerTec07008_MSaude.pdf > Acesso em 07/05/2018.

MINISTÉRIO DO MEIO AMBIENTE, 2018. Disponível em :< http://www.mma.gov.br/ > Acesso em 21/05/2018.

MUNIZ, F., H., D., OLIVEIRA-FILHO, C., E. "Metais pesados provenientes de rejeitos de mineração e seus efeitos sobre a saúde e o meio ambiente. Universitas: Ciências da Saúde, v. 4, p. 83-100, 2006.

NOWOSAD, J., KUCHARCZYKA, D., LUCZYŃSKA, J. Changes in mercury concentration in muscles, ovaries and eggs of European eel during maturation under controlled conditions, Ecotoxicology and Environmental Safety, v.148, p. 857-861, 2018.

OLIVEIRA, P., LÍRIO, V., A., CANHOTO, C., GUILHERMINO, L.,Toxicity of mercury and post-exposure recovery in Corbicula fluminea: Neurotoxicity, oxidative stress and oxygen consumption, Ecological Indicators, v.91, p. 503-510, 2018.

PENNA, G., C., "Efeitos da mineração no meio ambiente", Jornalismo Ambiental, (2018). Disponível em: < http://www.oeco.org.br > Acesso em 17/05/2018.

REIDLER, L., V., M., N., GUNTHER, R., M., W., III-117 - Gerenciamento de resíduos constituídos por pilhas e Baterias usadas. IN: Congresso Interamericano de Engenharia Sanitária e Ambiental, n. 27, 2000, São Paulo, ABES Associação Brasileira de Engenharia Sanitária e Ambiental, p. 1-12.

RYBAKA, M., KOŁODZIEJCZYKB, A., JONIAKA, T., RATAJCZAKC, I., GĄBKAD, M. Bioaccumulation and toxicity studies of macroalgae (Charophyceae) treated with aluminium: Experimental studies in the context of lake restoration, Ecotoxicology and Environmental Safety, v. 145, p. 359-366, 2017.

VRYZAS, Z., Pesticide fate in soil-sediment-water environment in relation to contamination preventing actions, Current Opinion in Environmental Science \& Health, v. 4, p. 5-9, 2018. 
WAUCHOPE, R. D., JOHNSON, W. C., SUMNER, H. R., Foliar and soil deposition of pesticide sprays in peanuts and their washoff and runoff under simulated worstcase rainfall conditions, Journal of Agricultural and Food Chemistry 2004, v. 52, p.7056-7063, 2004.

ZHAN, J., LI, T., ZHANG, X., YU, H., ZHAO, L., Rhizosphere characteristics of phytostabilizer Athyrium wardii (Hook.) involved in $\mathrm{Cd}$ and $\mathrm{Pb}$ accumulation, Ecotoxicology and Environmental Safety, v.148, p. 892-900, 2018. 